Fourth International Conference on Sustainable Construction Materials and Technologies

http://www.claisse.info/Proceedings.htm

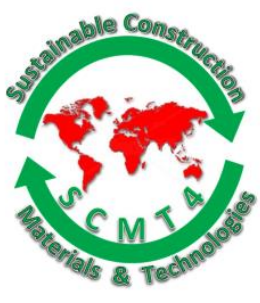

SCMT4

Las Vegas, USA, August 7-11, 2016

\title{
Using Fabric to Shape Appropriate Concrete Structures
}

\author{
Kaloyana Kostova $^{1 \mathrm{a}}$, Tim Ibell ${ }^{1 \mathrm{~b}}$, Antony Darby $^{1 \mathrm{c}}$, and Mark Evernden ${ }^{1 \mathrm{~d}}$ \\ ${ }^{1}$ University of Bath, Claverton Down, Bath, UK. ${ }^{1 a}$ Email: $\langle k . z . k o s t o v a @ b a t h . a c . u k\rangle,{ }^{1 b}$ Email:

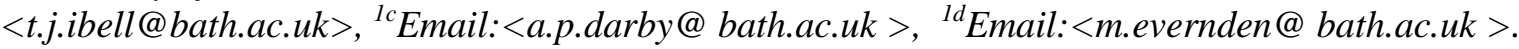

\begin{abstract}
Fabric formwork is an emerging method for construction of concrete structures, which offers a much greater freedom in creation of forms compared with the typical prismatic elements in modern built environment. While this can add a significant artistic value to architectural structures, there are many practical benefits associated with fabric formwork in terms of reduced construction time and costs, as well as the opportunity to shape structural elements appropriately and use the concrete material more efficiently. Research studies of fabric-formed beams carried out at the University of Bath, which aimed to develop practical design tools and construction guidance, have indicated that a minimum of $40 \%$ material savings are achievable with optimised design of fabric-formed concrete. Furthermore, reinforcing fabric-formed elements with FRP composite materials has shown significant advantages in terms of reinforcement installation and manufacturing techniques for producing FRP shear reinforcement with varying geometry. This paper presents experimentally tested construction approaches, proposed design methodology and experimental results, which validate the design method and demonstrate the possibility to build FRP-reinforced fabricformed beams exhibiting ductile behaviour.
\end{abstract}

\section{INTRODUCTION}

Reinforced concrete is a well-known and versatile material, which has a number of benefits, such as low maintenance, cost-effectiveness, inherent fire resistance, good sound insulation properties, high thermal mass and good seismic performance. Nevertheless, one main feature of concrete still remains underexploited, namely the mouldability of fresh concrete. Despite the opportunity to cast any form, concrete elements are usually built in inefficient prismatic shapes, consuming more material than structurally required. This could be attributed to two main reasons. Firstly, producing non-prismatic moulds, which cannot be re-used on a sufficiently large scale, would rarely be economically justified. Secondly, such elements would require more complex reinforcement detailing and preparation.

The use of flexible formwork, made of textile sheets, offers an alternative way to build concrete structures by utilising the natural force of gravity to create efficient forms. As the formwork is allowed to deflect, it requires a reduced number of external supports. Being considerably lighter than traditional formwork systems, fabric formwork also facilitates transportation and lifting processes. Over three decades of research in fabric-formed concrete have revealed the large scope of potential applications, including beam, slabs, columns, walls and shells (see Figure 1). In addition to their aesthetic appearance, fabric-formed structures have improved surface characteristics, influenced by the permeability of the typically used fabrics [Orr 2012]. For structural applications, the use of FRP reinforcement can be advantageous over traditional steel 
reinforcement [Kostova et al. 2012], while use of novel glass fibre textile reinforced cement has been found more suitable than steel meshes for reinforcing thin-shell structures [Tysmans et al. 2011]. Achieving large shell spans has also been considered through use of hybrid cable net/fabric systems [Veenendaal et al. 2014], where fabric is draped over reusable cable nets.

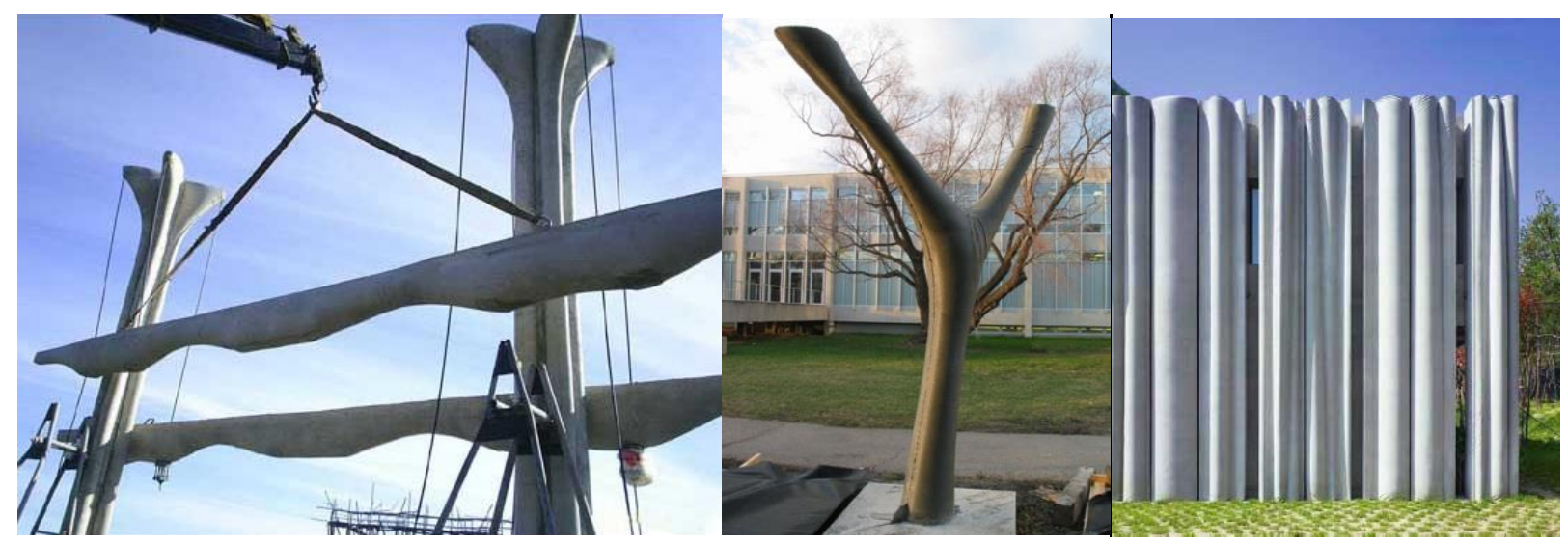

Figure 1. Examples of Fabric-Formed Concrete (Courtesy of Mark West)

\section{RESEARCH SIGNIFICANCE}

Currently the cement industry is responsible for about $8 \%$ of the total carbon emissions [Olivier et al. 2012], which indicates the large use of concrete material worldwide and the need to reduce its environmental impact. As discussed, prismatic concrete elements are not utilising the concrete material efficiently. Furthermore, it has been demonstrated by research studies that structurally optimised elements can use at least $27 \%$ less material compared with elements designed to current practice [Thirion 2011].

While fabric-formed concrete may not become a mainstream construction method in the immediate future, its development can help to meet long-term commitments for reducing embodied carbon of concrete structures. In fact, the idea of fabric formwork is not entirely new. Historical patents reveal inventors such as Waller who experimented with flexible formwork and cementitious materials at the beginning of the last century [Veenendaal 2011]. The marine industry has employed fabric formwork construction for protection mattresses and underwater concreting application. More recently Fab-form Industries has offered fabric formwork systems for circular columns and foundations, while wall construction methods, developed by the practicing architect Kenzo Unno, are used in Japan. The significance of the present-day research is to provide a transition from these very limited proprietary applications to a profound use of fabric formwork, which could allow the design of optimised structures. Such a significant change in the current practice, however, requires the development of experimentally validated design methodology, computational tools and construction methods to be offered to the industry.

\section{SCOPE OF RESEARCH}

How flexible? A major question the research in fabric formwork has to answer is whether it is feasible to design and build fabric-formed concrete for load-bearing structures. The design implications of using flexible formwork include analysis of complex shapes not known in advance combined with optimisation methods for structural efficiency. Design and provision of shear reinforcement could be particularly problematic for elements with varying cross sections along their length. 
The implications in terms of constructability are equally demanding. Many established methods for reinforcement scheduling, anchorage and installation cannot be directly used in flexible formwork, for example cover formers. Matching the profiles of pre-deformed steel bars and the optimised concrete elements depends both on the capability to predict the final hardened shape and the construction tolerances. Therefore, a high level of confidence in what tolerances are achievable and how they affect the structural performance is required to demonstrate the feasibility of fabric-formed concrete.

Previous research studies at the University of Bath. The University of Bath has a ten-year history of research in fabric formwork. Initial studies have been aimed at finding empirical shape expressions for optimised fabric-formed beams cast in fabric draped trough a horizontal opening, shown in Figure $2 \mathrm{a}$ [Bailiss 2006; Garbett 2008], followed by developing an iterative numerical method based on the theory of elasticity [Foster 2010]. Orr [2012] designed and tested a number of fabric-formed double T-beams (see Figure $2 \mathrm{~b}$ ) and demonstrated that their use could lead to $40 \%$ material savings for a typical multi-storey frame building. The study also included investigation of shear behaviour and appropriate methods for shear design of tapered beams. However, the production of suitable shear reinforcement remains an area for further research. Other identified constructability problems include provision of adequate concrete cover to reinforcement and end anchorage in optimised sections, where anchorage hooks or bends cannot fit due to reduced structural depth [Garbett 2008].

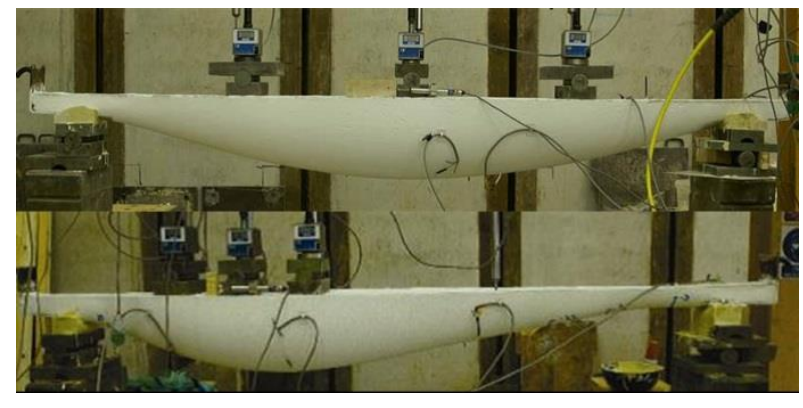

a. Optimised beams [Bailiss 2006]

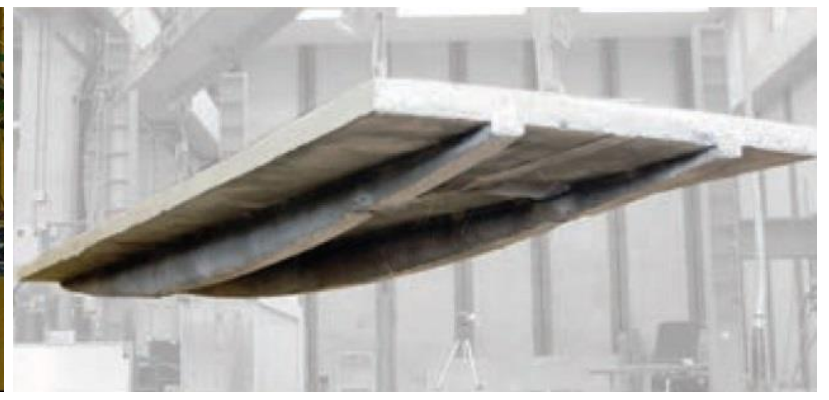

b. Double T-beams [Orr 2012]

\section{Figure 2. Fabric-Formed Beams cast at the University of Bath}

Research objectives. The need to pre-deform steel bars and ensure adequate concrete cover thickness may limit significantly the opportunity to benefit from the flexibility of fabric formwork, if it does not lead to an entirely unacceptable risk of reinforcement corrosion. FRP composite materials have high resistance to corrosion, light weight and due to their flexibility can even be installed in curves of large radius without pre-forming. For these reasons, FRP reinforcement has been studied as an appropriate alternative to steel bars in fabric-formed concrete and the following objectives have been set and achieved:

- Develop a design methodology and computational tools, suitable for both FRP and steel reinforcement, based on experimental testing of fabric-formed beams

- Develop a practical solution for end anchorage, suitable for relatively small beam depths

- Demonstrate that FRP reinforcement is suitable for building ductile fabric-formed concrete elements by adapting existing methods for rectangular beams

- Develop appropriate techniques for producing FRP shear reinforcement with varying geometry

\section{CONSTRUCTION METHODS}

Fabric formwork can be applied in the form of reusable flat sheets for building a variety of forms. Pleats and wrinkles in the fabric material transferred to the concrete surface are generally regarded as architectural features. However, stitching fabric patterns can help to avoid them or create more intricate forms. The novel 
construction ideas presented herein explore the advantages of FRP reinforcement and fabric, in addition to providing an innovative anchorage system for reinforcing bars. While these ideas may have not been fully developed for industrial application yet, they certainly help to show the basic principles in utilising the flexibility and light weight of fabric formwork and FRP reinforcement.

Self-forming fabric-formed beam reinforcement. Figure 3 illustrates a method for creating curved reinforcement profiles by attaching FRP bars to fabric prior to pouring of concrete. In this case plastic ties have been used, which can be easily cut once the concrete has hardened. Plastic ties have also been successfully applied to manipulate the shape of beam cross sections and reduce the breadth near the neutral axis zone, as shown in Figure 3. The advantage of plastic ties is that they can be pre-attached, improving the construction accuracy, and need minimal or no grouting after removal.

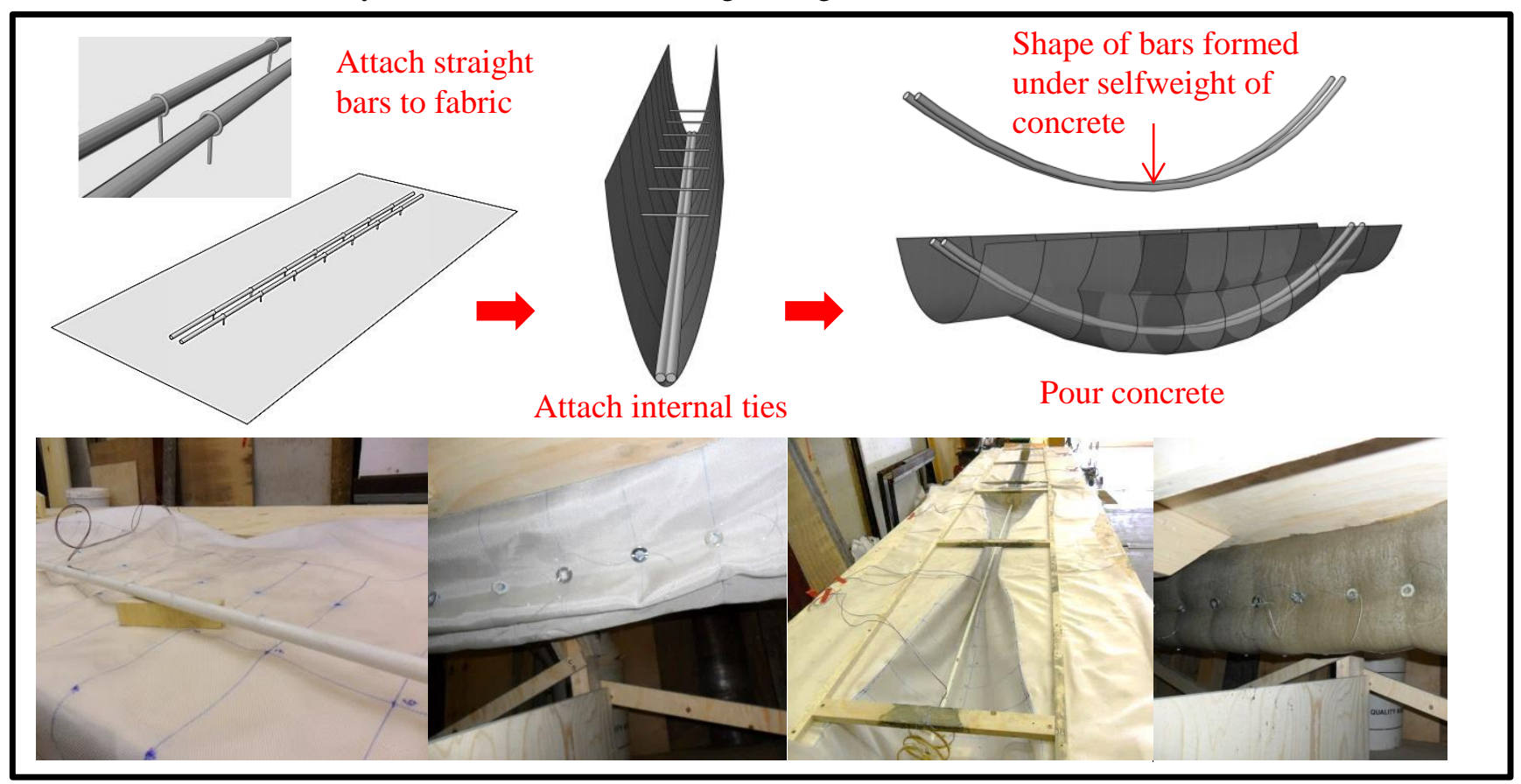

Figure 3. Self-forming method for FRP reinforcement

Splayed anchorage system. A novel method for anchoring reinforcing bars has been developed at the University of Bath. The method involves splaying the ends of a bar to create wedge anchors, which can further be confined by helical reinforcement to prevent brittle failure of the surrounding concrete, as described by Figure 4. The effectiveness and applicability of the proposed system for FRP bars in sections of limited depth has been confirmed by experimental investigation and a theoretical model predicting the anchorage bond-slip behaviour developed by Kostova et al. [2013].

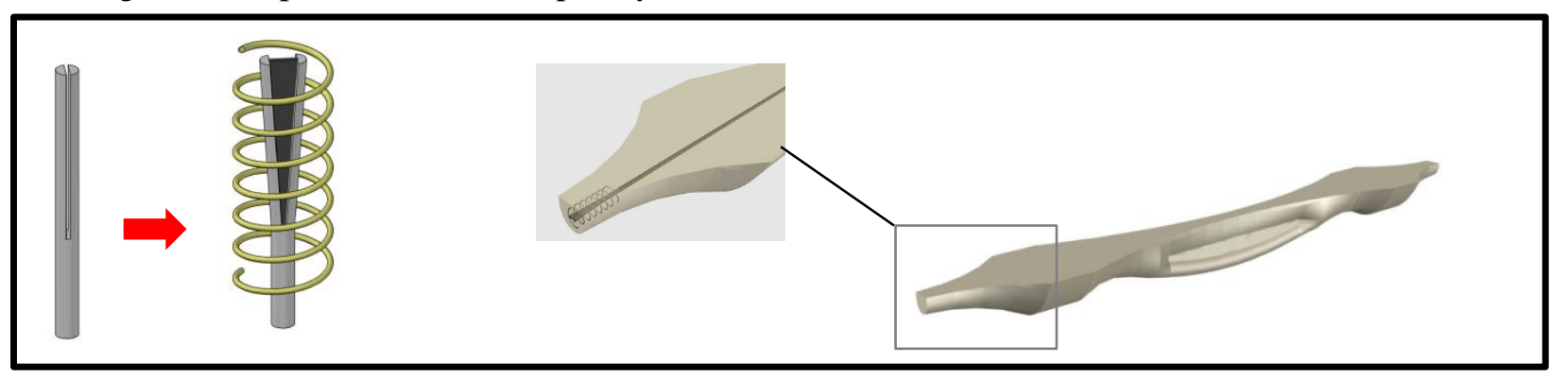

Figure 4. Splayed Anchorage Preparation and Installation 
Foldable pre-stitched column formwork. The last presented method, shown in Figure 5, involves prestitching and pre-attaching fabric formwork to portable frames, which can then be folded for ease of transportation. FRP reinforcement can also be pre-attached to the stitched fabric. An experimental construction of small scale columns has demonstrated that by following the described principle, building shapes of varying level of complexity would need equal effort on site. The preparation works could require more or less advanced skills but would generally be less demanding than design and manufacturing of upholstery products.
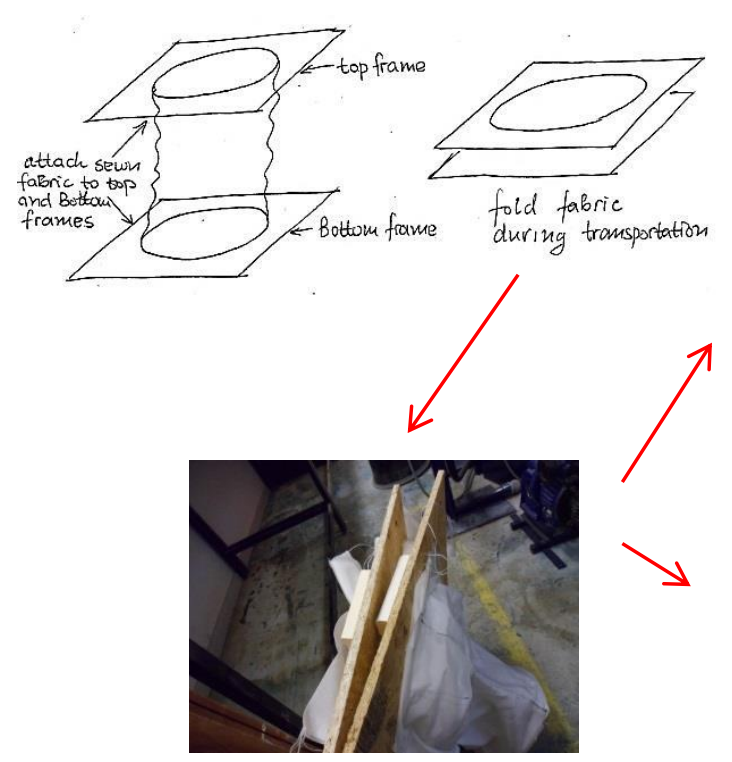
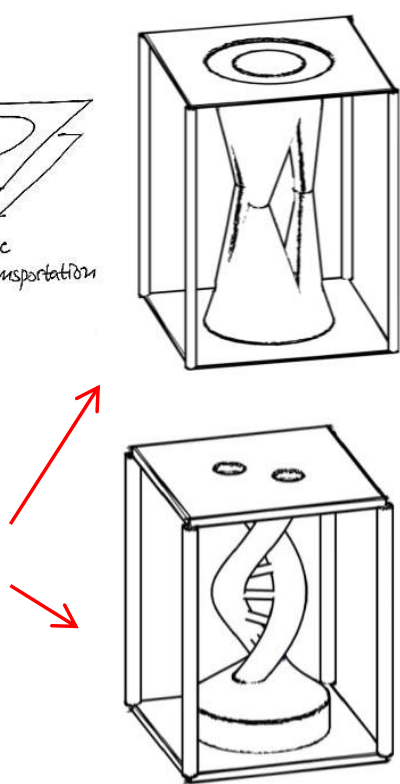
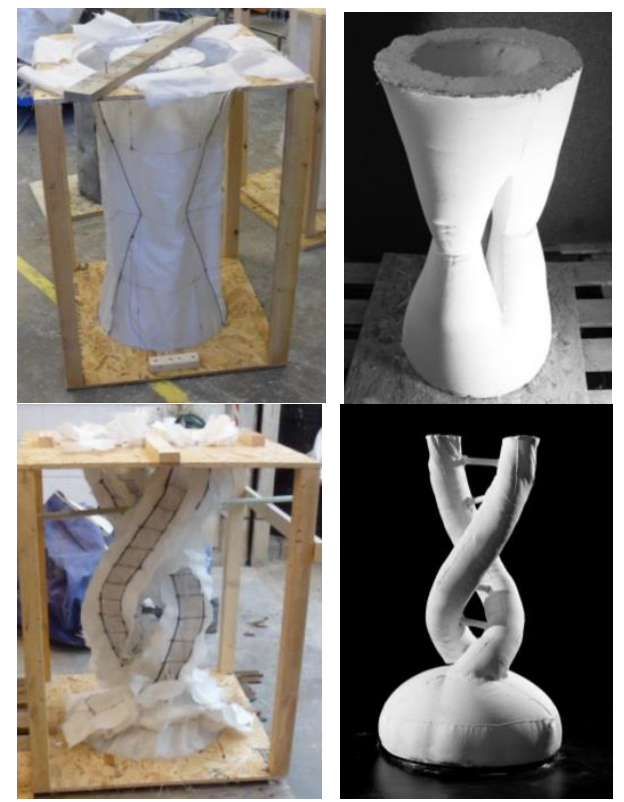

Figure 5. Fabric-formed Columns

\section{DESIGN METHODOLOGY}

Design problem. The design of fabric-formed elements would usually require an automated process integrating three components, as shown in Figure 6. In addition, boundary conditions, such internal ties, need to be defined depending upon the chosen method for construction.

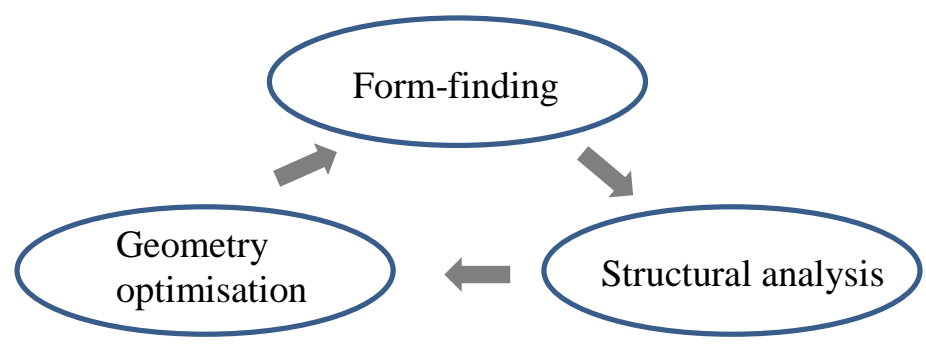

Figure 6. Design Process

Form-finding and optimisation. In order to optimise the geometry of a fabric-formed element, a set of variables defining each cross section has to be established. As confirmed by previous studies, for a beam element cast in a fabric freely hung fabric supported continuously along two edges, the depth of a cross section $h$ depends on the top breadth $b$ and the perimeter of the fabric [Bailiss 2006]. Therefore, $b$ and $h$ can 
be optimised in order to determine the required hung perimeter at discrete sections along the length, as illustrated in Figure 7. However, for sections with small $b / h$ ratio, such as the sections near midspan of a simply-supported beam, the resulting bulging shapes are fairly inefficient in terms of material use and would benefit from a restraint at an appropriate depth level. This could be achieved by internal plastic ties, as described; standard steel formwork ties inserted in plastic sleeves; or rigid web formers internally tied or externally supported by vertical side frames, which may be found more suitable for precast elements.
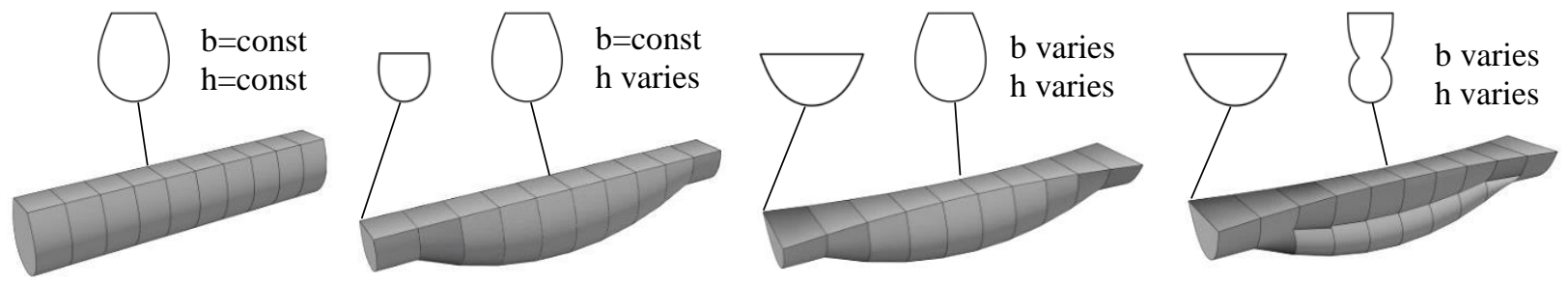

Figure 7. Optimisation of Fabric-formed Beam Geometry

The proposed method for form-finding developed at the University of Bath is appropriate for sectional analysis and optimisation at discrete sections. Figure 8 explains the procedure to be implemented for each cross section.
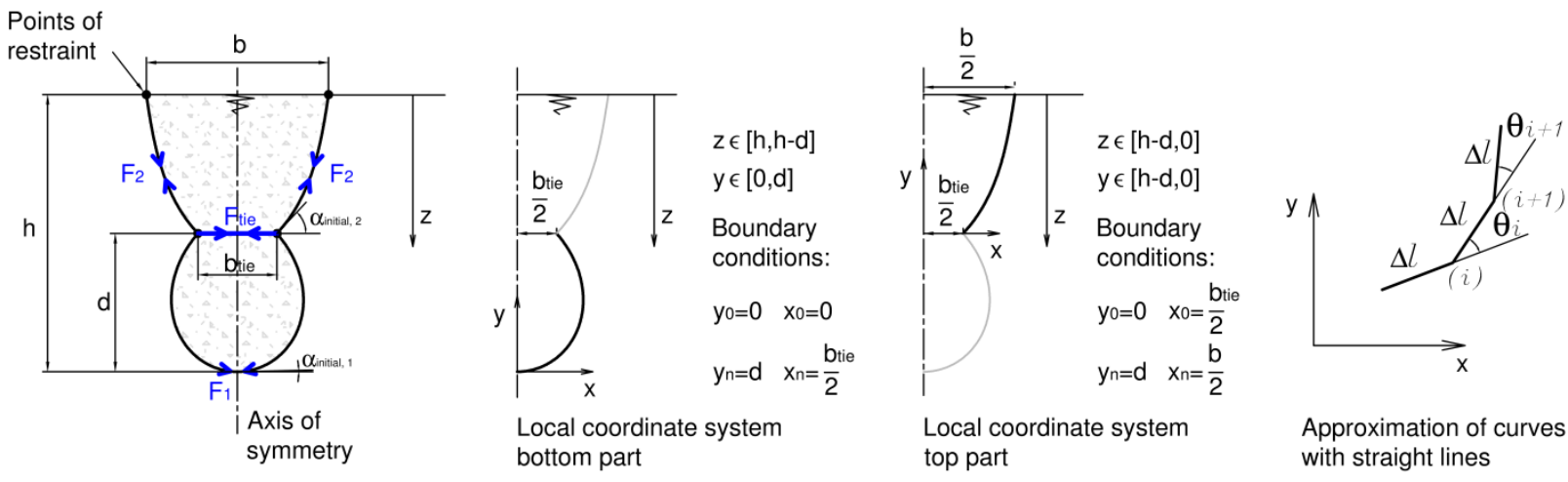

Figure 8. Form Finding Procedure

The shapes are formed under the hydrostatic pressure of the wet concrete and would normally be symmetrical about their vertical axis, which allows analysing only half of the section. The perimeter of the half under consideration is split into separate curves between the points of physical restraints, such as the supported edge and internal ties. The length of each curve is represented by straight lines with sufficiently small length $\Delta l$. In order to determine the final shape, the coordinates at each point $i$ are expressed in a local coordinate system defined for each curve. Every successive coordinate is a function of the previous coordinate, the sum of the angles $\theta_{l} \div \theta_{i}$ and the initial angle $\alpha_{\text {initial }}$ of the lowest straight line and the horizontal axis. It can be shown that the angle $\theta_{i}$ is directly proportional to the hydrostatic height $z_{i}$ at each point along the curve, which leaves two unknowns, $\alpha_{\text {initial }}$ and the coefficient of proportionality relating $\theta_{i}$ to $z_{i}$. However, for a freely hung fabric the initial angle $\alpha_{\text {initial }}$ is half of the angle $\theta_{l}$ due to symmetry. The coefficient of proportionality is found from the given boundary conditions. The initial angles of any upper curves can be found from equilibrium of forces at the points of restraint. Therefore, for the presented case in Figure 8, the final section is fully described by the indicated dimensions $b, h, d, b_{t i e}$, and the coefficients of proportionality for the top and bottom curves. 
Concrete confinement and shear reinforcement. A major drawback in the use of FRP reinforcement is the lack of ductility of FRP materials, which usually require overeinforced design to utilise any ductility of concrete in compression [Nanni 2003]. Nevertheless, the strain capacity of concrete is limited and cannot lead to a satisfactory and safe failure mode. Confinement of concrete in the compression zone of a beam has been successfully applied for enhancing the performance of FRP-reinforced rectangular beams, demonstrating that brittle failure could be prevented due to a significant increase in the ultimate strain of confined concrete [Ibell et al. 2009]. Whitehead [2002] tested concrete specimens confined with helical aramid FRP reinforcement, which exhibited ductile behaviour, reaching a maximum strain of $1 \%$, as indicated on the idealised stress-strain diagram in Figure 9a. In a beam the helical reinforcement will be positioned as close as possible to the compression surface. While the concrete around the helix loses integrity beyond the 0.0035 strain limit, the confined concrete remains in place and can reach a rectangular stress block near failure, as Figure $9 \mathrm{~b}$ indicates. The actual stresses in the confined and unconfined concrete have to be evaluated separately beyond the peak value.

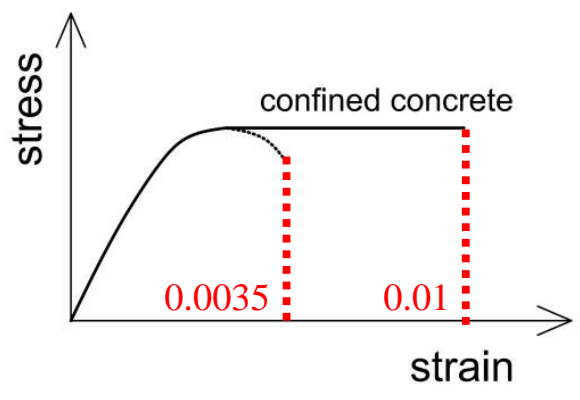

a. Stress-strain curve

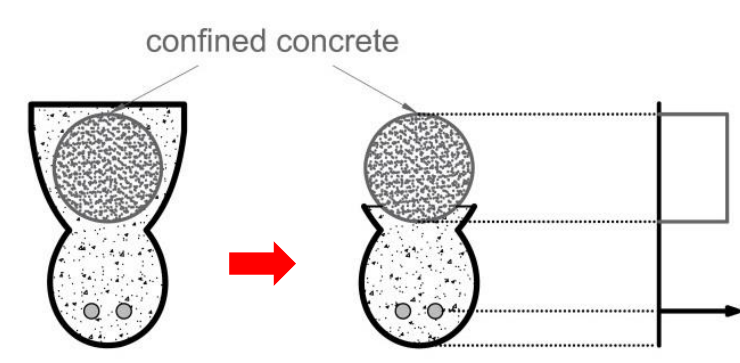

b. Sectional analysis

\section{Figure 9. Analysis of Beam with Confined Concrete in the Compression Zone}

Improving the ductility in bending, however, could make the shear behaviour more critical. A viable solution for producing shear reinforcement made of resin-impregnated carbon fibres wound in varying shapes has been successfully tested for fabric-formed beams, indicating a $100 \%$ increase in the shear capacity in comparison with unreinforced beam. A dual system, illustrated in Figure 10, comprising both confining and shear spiral reinforcement has been developed for fabric-formed beams. The shear spiral can be shaped directly onto the curved longitudinal bars for better accuracy.

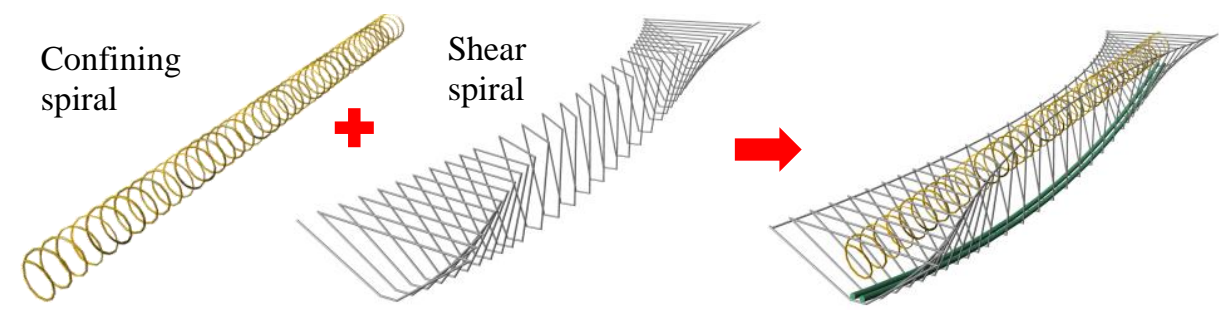

Figure 10. Dual Spiral FRP Reinforcement for Fabric-formed Beams

Experimental verification of design. A number of test beams have been built and tested to investigate the predictability of geometry and load-deflection behaviour of fabric-formed beams. Various techniques have been used to record the as-built dimensions, including laser scanning, manual measurements using profile gauges and physical slicing of beams. The results indicated that construction tolerances as low as $2 \mathrm{~mm}$ could be achieved for critical sections near midspan (refer to Figure 11a). The depth of sections near supports has been found often to be greater than the predicted, which was typically affected by a reduced 
top opening due to construction inaccuracies in the shape of the supporting frames, as can be seen in Figure $11 b$.

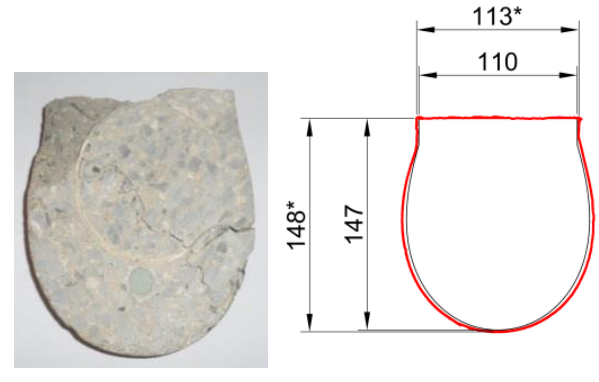

a. Typical middle section
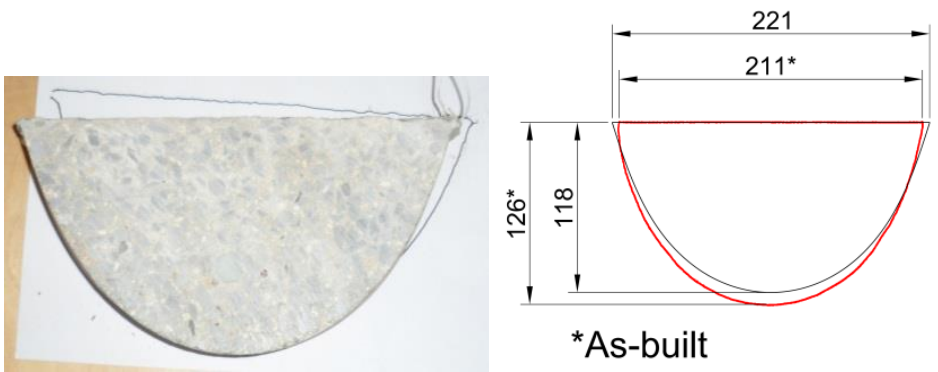

b. Typical end section

Figure 11. As-built profiles of fabric-formed beams

The load-deflection response of beam specimens with confined and unconfined concrete in the compression zone is presented in Figure 12a. The compared specimens had the same geometry, the same longitudinal reinforcement comprising one $10 \mathrm{~mm}$ diameter glass FRP sand-coated V-Rod HM bar, produced by Pultrall Inc. and the same shear reinforcement produced of carbon fibre tow Sigrafil C Type from SGL Group. Only one specimen contained confining reinforcement made of manually impregnated aramid fibres set in a helical shape of $90 \mathrm{~mm}$ diameter and $30 \mathrm{~mm}$ pitch. The presented results indicate the more ductile behaviour of the confined concrete beyond the peak load. The experimental curve has been compared with predicted responses based on both the design and the as-built geometry (refer to Figure 12b). As can be seen, both predictions produce similar curves corresponding well to the experimental results, showing an insignificant effect of the as-built deviations from design geometry.

Figure 13 demonstrates the capability to predict the full load-strain response for beams with confined and unconfined concrete. The presented photographs confirm the expected failure modes. The unconfined concrete in Figure 13a fully collapsed at failure, while the confined concrete in Figure 13b remained intact inside the confining reinforcement until the end of the load test sustaining high post-peak load, which could be further increased by reducing the concrete cover to the top surface.

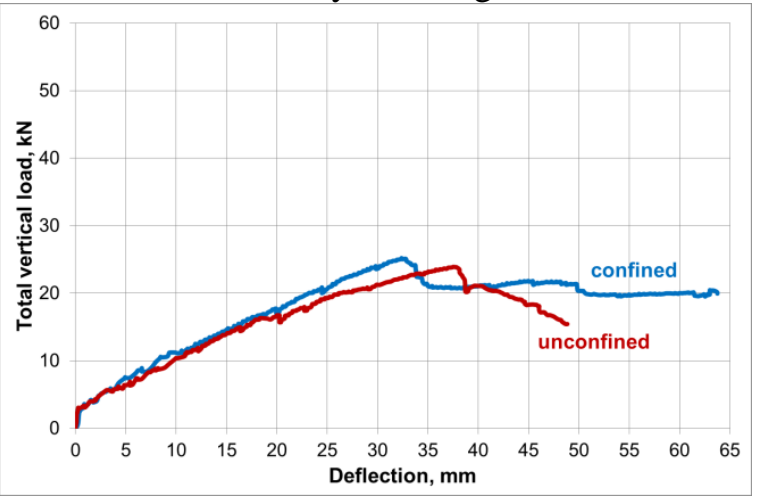

a. Confined vs Unconfined

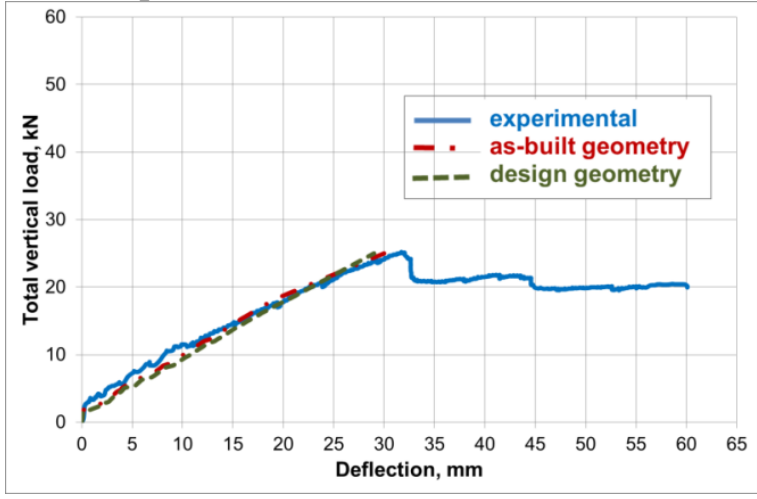

b. Experimental vs Predicted

Figure 12. Load-deflection curves for fabric-formed beams 


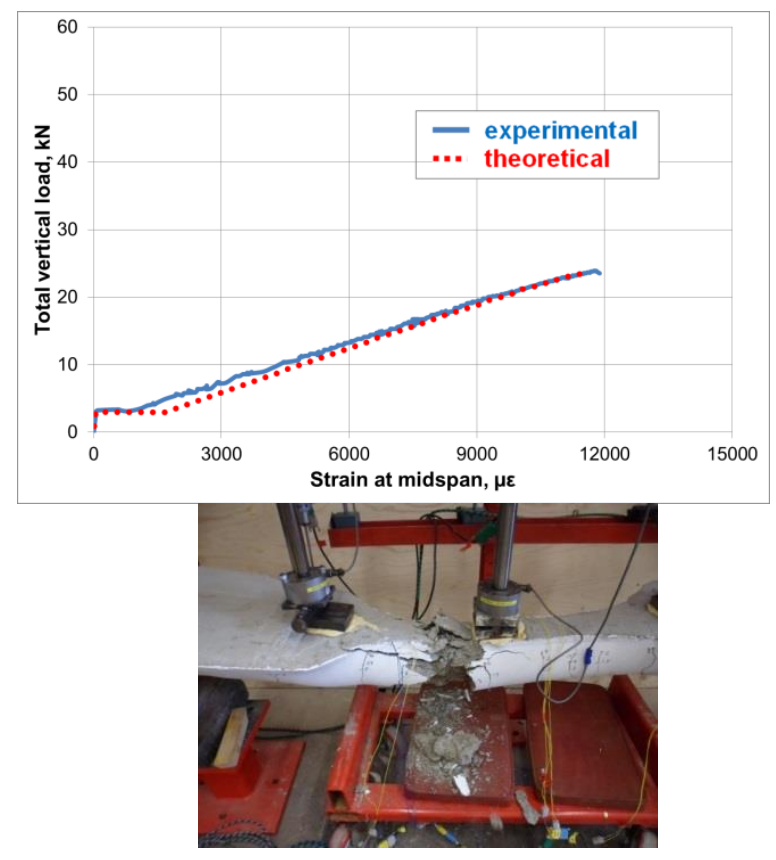

a. Unconfined specimen

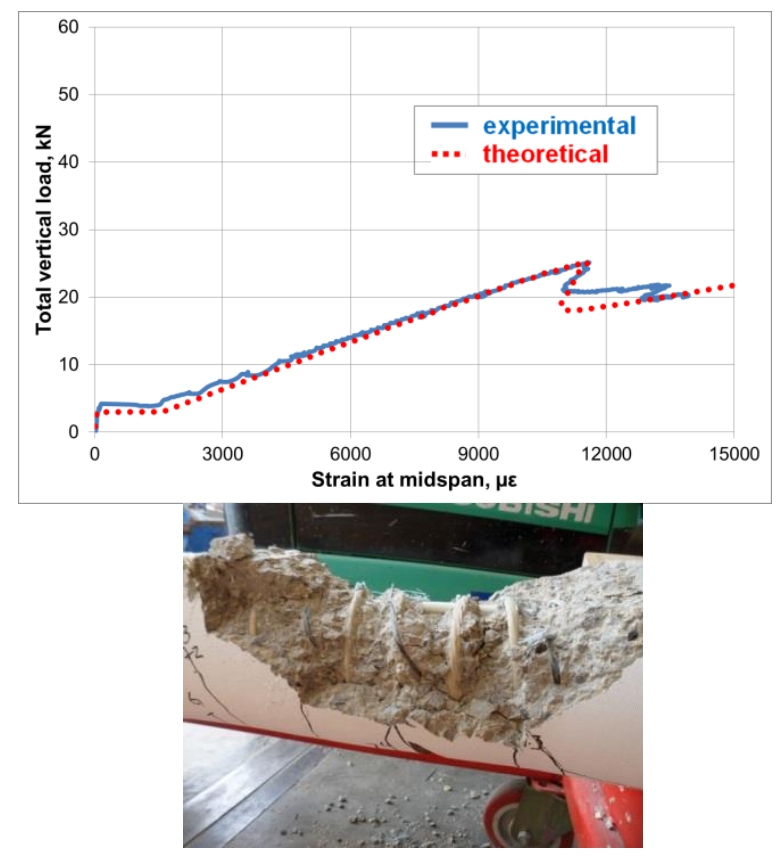

b. Confined specimen

Figure 13. Load- Strain in FRP Bar Curves and Failure Mechanisms

\section{CONCLUSION}

The following conclusions can be drawn from the results and discussions provided in the paper:

- Fabric formwork is feasible, providing a novel way to build beautiful and efficient concrete structures

- FRP reinforcement can resolve major buildability issues, such as uncertainty in ensuring protective cover to steel reinforcement and producing shear reinforcement with varying geometry

- Ductility of FRP-reinforced fabric-formed elements can be achieved by FRP confining spiral reinforcement in the compression zone of concrete, averting brittle failure

- The developed splayed anchorage system is suitable for optimised sections with reduced depths

\section{FUTURE OF FABRIC FORMWORK}

New research at University of Bath is exploring the possibility for integration of sensing systems in participating fabric formwork for measuring the structural, thermal and serviceability performance of buildings. Collecting and analysing big data could ultimately lead in the long term to a major change in the current design practice and the development of iterative prototypical design, shaping the future built world.

\section{ACKNOWLEDGEMENTS}

The authors gratefully acknowledge the financial support of the Leverhulme Trust, and the help of the technical staff in the Structures Laboratory of the Department of Architecture and Civil Engineering at the University of Bath. 


\section{REFERENCES}

Bailiss, J. (2006). "Fabric-formed concrete beams design and analysis." MEng Dissertation, University of Bath.

Foster, R. (2010). "Form finding and analysis of fabric-formed concrete beams." MEng Dissertation, University of Bath.

Garbett, J. (2008). "Bone growth analogy for optimising flexibly formed concrete beams." MEng Dissertation, University of Bath.

Kostova K.Z., Ibell T.J., Darby A.P., and Evernden M.C. (2012). "Advanced Composite Reinforcement for Fabric Formed Structural Elements", In: Proceedings of Second International Conference on Flexible Formwork (icff2012), 27 - 29 June 2012, Bath, UK.

Kostova K.Z., Ibell T.J., Darby A.P., and Evernden M.C. (2013). "Novel splayed anchorage system for internally reinforced concrete members", In: Proceedings of 11th International Symposium on Fiber Reinforced Polymer for Reinforced Concrete Structures (FRPRCS-11), 10 - 12 September 2013, Belfast, UK.

Ibell, T., Darby, A., and Denton, S. (2009). "Research issues related to the appropriate use of FRP in concrete structures." Construction and building materials, 23, 1521-1528. doi:10.1016/j.conbuildmat.2008.05.011.

Nanni, A. (2003). "North American design guidelines for concrete reinforcement and strengthening using FRP: principles, applications and unresolved issues." Construction and building materials, 17 (6-7), 439 - 446. doi:10.1016/S0950-0618(03)00042-4

Olivier, J.G.J., Janssens-Maenhout, G., Muntean, M., and Peters J.A.H.W. (2012). "Trends in global CO2 emissions.” The Hague/Bilthoven: PBL Netherlands Environmental Assessment Agency, (publication number: 500114022).

Orr, J.J. (2012). "Flexible formwork for concrete structures," PhD dissertation, University of Bath.

Tysmans, T., Adriaenssens S., and Wastiels J. (2011). "Form finding methodology for force-modelled anticlastic shells in glass fibre textile reinforced cement composites." Engineering Structures, 33, 2603 2611. doi:10.1016/j.engstruct.2011.05.007.

Veenendaal, D., and Block, P. (2014). "Design process for prototype concrete shells using a hybrid cablenet and fabric formwork." Engineering Structures, 75, 39-50. doi:10.1016/j.engstruct.2014.05.036.

Veenendaal, D., West, M., and Block, P. (2011). "History and overview of fabric formwork: using fabrics for concrete casting." Structural Concrete, 12 (3), 164-177. doi:10.1002/suco.201100014.

Whitehead, P. A. (2002). "Shear Strength of Concrete containing Fibre- Reinforced-Plastic reinforcement." $\mathrm{PhD}$ Thesis, University of Bath. 